\title{
Silanized cereal straw as a novel, functional filler of natural rubber biocomposites
}

\author{
Marcin Masłowski $\cdot$ Justyna Miedzianowska $\cdot$ Krzysztof Strzelec
}

Received: 11 September 2018/Accepted: 19 October 2018/Published online: 23 October 2018

(C) The Author(s) 2018

\begin{abstract}
The aim of the presented research paper was to modify the biofiller in the form of milled cereal straw with 3-aminopropyl(diethoxy)methyl silane, and apply it to the natural rubber. To determine the material properties, an in-depth characterization of both the treated lignocellulosic material and the composites was studied. On the basis of thermogravimetric analysis, scanning electron microscopy, infrared spectroscopy and analysis of contact angle measurements, it was found that the silanization process significantly influenced thermal stability and hygroscopicity of the straw, its hydrophobicity as well as dispersion in polymeric matrix. Analyses of the new
\end{abstract}

composites included static and dynamic mechanical properties, hardness, and barrier and damping properties, all of which showed improvement. This was because of improved interactions at the filler-elastomer, which resulted from better adhesion of the treated bio-additive to natural rubber. Biocomposites have also demonstrated greater resistance to flammability as well as thermo-oxidative aging processes. The research clearly indicates the application potential of these new multifunctional and biocompatible materials.

M. Masłowski ( $₫) \cdot$ J. Miedzianowska · K. Strzelec

Institute of Polymer and Dye Technology, Lodz

University of Technology, Stefanowskiego 12/16,

90-924 Lodz, Poland

e-mail: marcin.maslowski@p.lodz.pl 


\section{Graphical abstract}

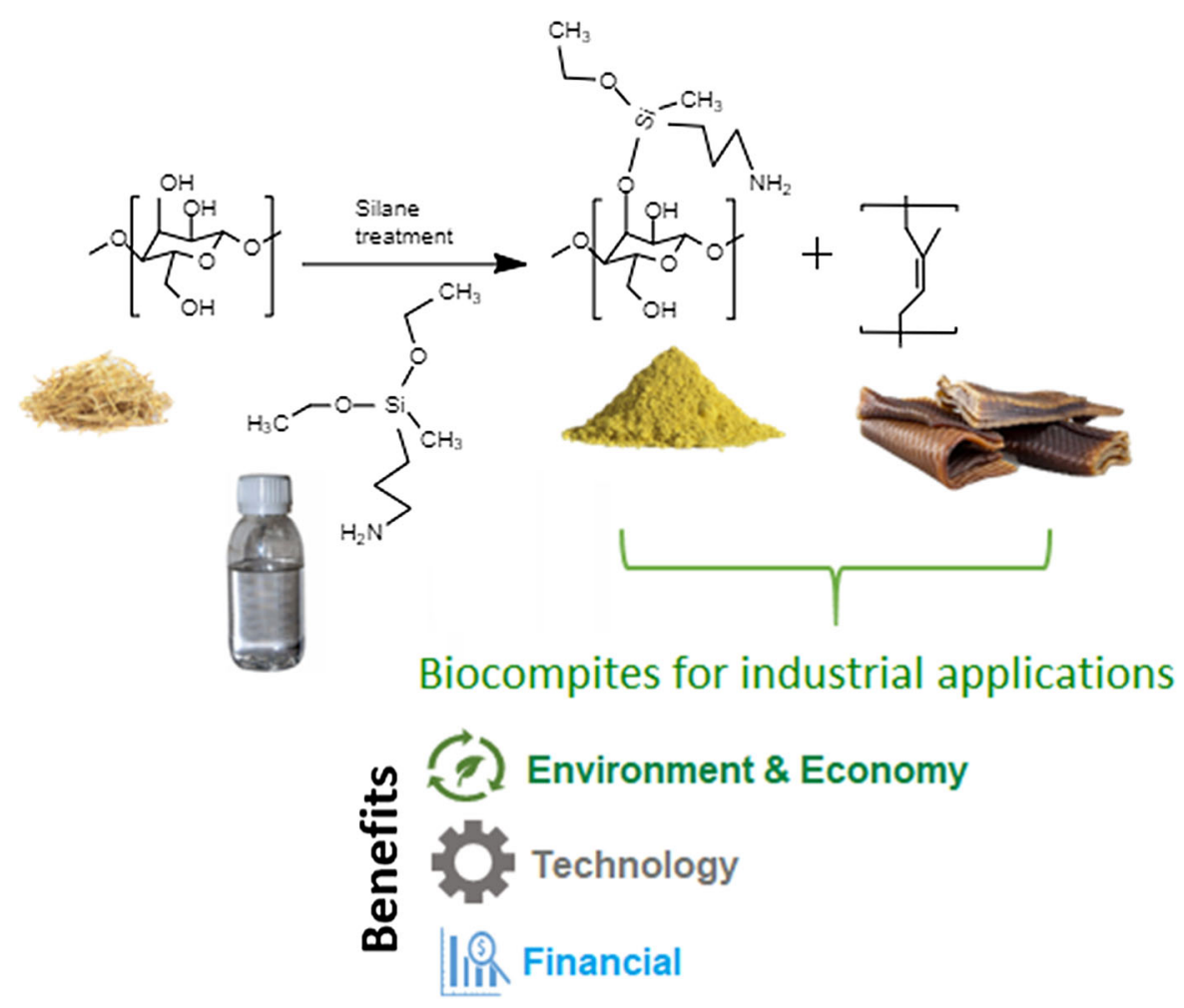

Keywords Straw $\cdot$ Silane treatment $\cdot$ Natural rubber $\cdot$ Lignocellulosic filler $\cdot$ Biocomposites

\section{Introduction}

The expanded search for new, high-performance, ecofriendly materials has been one of the most important research directions recently. Biocomposites based on agrowaste and various polymer matrices reflect their wide potential resulting from today's demand for multifunctional materials, environmental issues and economic benefits, as well as the management of agricultural by-products (Chun and Husseinsyah 2014; Chun et al. 2013; Ramli et al. 2011; Trigui et al. 2013). Natural fiber hybrid composites, where synthetic fibers are replaced by the natural ones represent better electrical resistance, good mechanical properties, good thermal and acoustic insulating properties and higher resistance to fracture. Not without significance is their lower cost, biodegradability, recyclability and lower density (Sathishkumar et al. 2014; Sanjay and Yogesha 2017; Yusriah et al. 2014; Dhakal et al. 2015; Vijaya Ramnath et al. 2014; Deng et al. 2016). The most widely known and used natural-cellulosic fillers are fibers basically extracted from soft and hard wood, cotton, flax, sisal, kenaf, jute, hemp, starch and cereal plants (La Mantia and Morreale 2011).

Straw is a ripe and dried blade of cereal plants, legumes, rape and flax. Most often, it is a by-product of plant production, estimated in millions of tons per year, depending on the country. It is a rich source of cellulose. Like most plant fibers, straw is composed of cells that in their structure have crystalline areas of cellulose called microfibrils. These areas are joined by an adhesives, such as lignin and hemicellulose. There are many methods of managing this valuable product, among others: as a bedding of livestock, as an additive to fodder and fertilizers or as a biomass for obtaining energy during combustion. However, each of these methods has some limitations, which causes the occurrence of huge straw surplus accumulated in production processes. 
Our previously published work has proven (Masłowski et al. 2017, 2018a, b), that it is possible to use straw as a functional additive to elastomeric materials. Such biocomposites are characterized by improved properties, in particular mechanical strength, barrier, tear resistance, improved damping or flame retardant parameters. However, the biggest challenge remains the adhesion of the hydrophilic filler to the hydrophobic polymer matrix which most affects the mechanical properties of the composites. To enhance the effectiveness of interfacial bonding, fibre surface needs to be modified. In general these processes can be classified into physical, chemical, physical-chemical, biological methods and their combinations. Application of different methods of chemical modifications of natural fibers clearly indicates the validity of their use, demonstrating material advantages based on fiber-matrix interactions improvements. These are mainly acid or alkali treatment, acetylation, peroxide treatment or treatment with various coupling agents, etc. (Gámez et al. 2006; Murciano Martínez et al. 2015; Heggset et al. 2016; Eqra et al. 2014; Bledzki et al. 2008; Mwaikambo and Ansell 1999; Kalaprasad et al. 2004; Keener et al. 2004; Mohanty et al. 2004).

One of the most promising methods is silanization, where silane coupling agent modifies fibre surfaces and stabilizes the composite material. This hydrophilic or hydrophobic compound reduces the number of cellulose hydroxyl groups at the fiber-matrix interface. In the presence of moisture, hydrolysable alkoxy group leads to the formation of silanols. As a result of the reaction of the silanol with the hydroxyl group of the fiber, stable covalent bonds with the cell wall are observed. These bonds then undergo chemisorbtion on the surface of the fiber. The Si-alkyl group lowers the surface tension and improves wetting properties. Hydrocarbon chains restrain the swelling of the fiber by creating a crosslinked network in modified biocomposites (Ramamoorthy et al. 2015; Thakur et al. 2014; Kabir et al. 2012).

The application of straw as a natural filler and an alternative to conventional reinforcing materials, due to its bio-character and competitive specific mechanical properties combined with aspects of chemical modification in the form of silanization, is crucial in the development of such materials based on biocomposites. Authors wanted to assess the impact of the modification of lignocellulose material on multifunctional properties (mechanical, thermal, barrier, fire, etc.) of NR. An unquestionable scientific novelty was the use of straw as a source of biosupplement. This cellulose-rich material shows the potential paths of its use and sets new directions for development. Until now, only a few studies were devoted to use of natural rubber as polymer matrix for fiber based biocomposites, which further underlines the importance of conducted researches.

The obtained results explained the major drawback of natural fibers as elastomer composites reinforcements. They are depending on the elastomeric matrix used, the filler type and quantity, the adhesion promoter as silane used and the processing techniques. Application of silane-coupling agent is a recent and promising field having beneficial effect on the functional properties (i.e. static and dynamic mechanical properties, hardness, barrier and damping properties) of the ensuing straw-based natural rubber vulcanizates. Moreover dynamic mechanical analysis proved that poor compatibility between the hydrophilic fibers and the hydrophobic polymer matrix can be overcome due to proper chemical modification. In addition improved compatibility between fiber and composite surface reflected as wettability has been confirmed by water droplet contact angle measurements. Furthermore the morphology of straw and dispersion of straw in natural rubber vulcanizates was analyzed by scanning electron microscopy images.

\section{Experimental}

\section{Materials}

The natural rubber (NR, RSS II) containing cis-1,4polyisoprene was obtained from Torimex Chemicals (Poland). This elastomer was vulcanized with sulfur (Siarkopol Tarnobrzeg, Poland), microsized zinc oxide (ZnO, Aldrich, Germany) and steric acid (SA, Avantor Performance Materials Poland) as the standard activators and 2-mercaptobenzothiazole (MBT, Aldrich, Germany) as accelerator.

Biofiller: cereal straw (wheat, rye, triticale, barley and oat) was obtained from local farms (Poland) and grinded by ball mill. For silane treatment, the fibers were allowed to react with 3-aminopropyl(diethoxy)methylsilane (Aldrich, Germany) by immersing them in a $5 \%$ (ratio to the straw) silane ethanol 

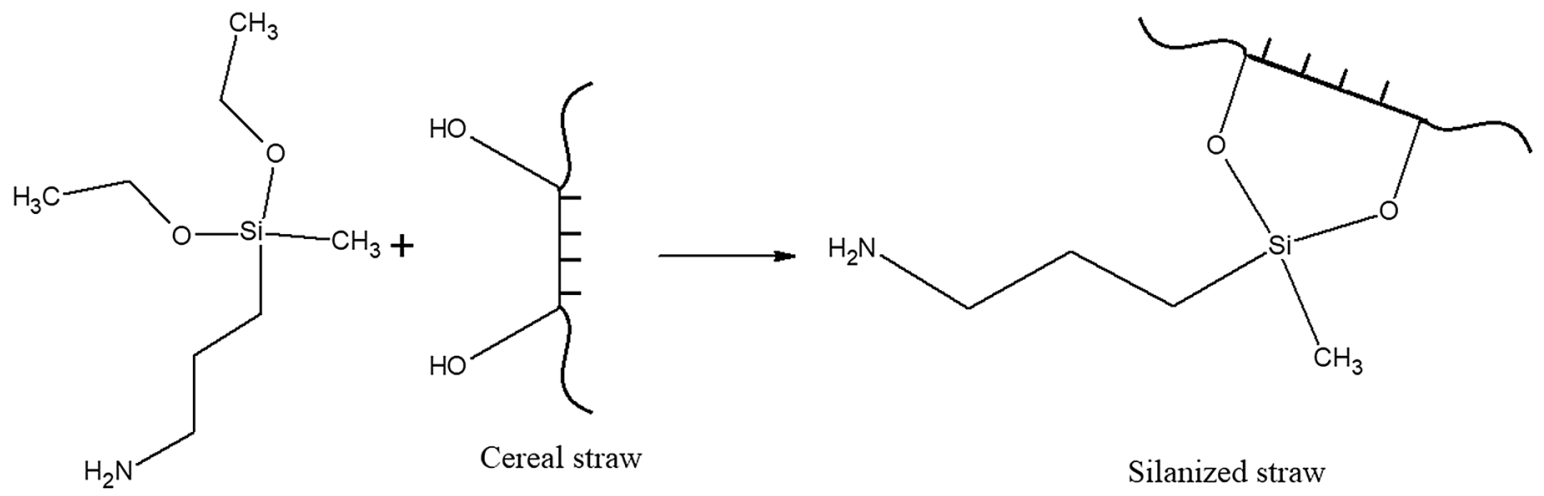

3-aminopropyl(diethoxy)methylsilane

Fig. 1 The scheme of silanization of cereal straw

solution and treatment with ultrasounds (Hielscher Ultrasound Technology, UP400S, Teltow, Germany) for $2 \mathrm{~h}$. Then, solvent was evaporated by using rotary evaporator(Heidolph, Laborata4001 efficient, Schwabach, Germany) and the residue (silanized straw) was dried at $70{ }^{\circ} \mathrm{C}$ to achieve constant mass (Fig. 1).

\section{Characteristic of straw}

The thermal stability of the straw was studied using a TGA/DSC1 (Mettler Toledo, Greifensee, Swiss) analyzer. The sample weight was kept at approx. $10 \mathrm{mg}$. Straw was heated from 25 to $600{ }^{\circ} \mathrm{C}$ in a argon atmosphere with a heating rate of $10^{\circ} \mathrm{C} / \mathrm{min}$.

The chemical structure of straw used in this study was characterized by Fourier Transform Infrared Spectroscopy (Thermo Electron, Nicolet 6700 spectrophotometer, Waltham, USA), 128 scans were taken between 400 and $4000 \mathrm{~cm}^{-1}$ with the resolution $8 \mathrm{~cm}^{-1}$. Single reflection diamond ATR crystal on ZnSe plate and DTGS/KBr detector was applied.
Straw was compressed into the form of pressurized discs using a hydraulic press. The static advancing contact angle between a water droplet $(10 \mu \mathrm{l})$ and the pressed fiber disc was measured using the sessile drop method on a goniometer (DataPhysics, OCA 15EC, San Jose, USA). The contact angle was measured from the captured images.

Preparation and characterization of rubber compounds

Rubber compounds with the formulations given in Table 1 were prepared using measuring mixer and laboratory two-roll mill. The mixing in a Brabender measuring mixer N50 at 50-60 ${ }^{\circ} \mathrm{C}$ lasted 8 min which included 4 min of plastification of rubber and 4 min of mixing rubber with the straw. Next, two-roll mill was used to mix the blend with the sulfur curing system and obtain rubber sheets.

Cure time and rheological parameters of the rubber mixtures were determined by an oscillating disk rheometer (Mon-Tech, MDR 300, Buchen, Germany)
Table 1 The compositions of rubber compounds

\begin{tabular}{lllllll}
\hline & Straw [phr] & NR [phr] & SA [phr] & ZnO [phr] & MBT [phr] & Sulfur [phr] \\
\hline Ref. sample (NR) & 0 & 100 & 1 & 5 & 2 & 2 \\
Pure straw & 10 & 100 & 1 & 5 & 2 & 2 \\
& 20 & & & & & \\
& 30 & & & & & \\
Silanized straw & 10 & 100 & 1 & 5 & & \\
& 20 & & & & & \\
& 30 & & & & & \\
\end{tabular}

phr parts per hundred parts of rubber 
according to ISO 3417 standard. Measurements of rheological properties were performed twice for each sample. The obtained results were repeatable, usually the measurement error did not exceed 0.05 . Next, the composition were cured in molds by using hydraulic press with electrical heating at $160{ }^{\circ} \mathrm{C}$ according to their respective $t_{90}$ values, obtained from the test of cure characteristics.

The crosslink densities $\left(v_{e}\right)$ of the vulcanizates were determined by their equilibrium swelling in toluene, based on the Flory-Rehner equation (Eq. 1) (Flory and Rehner 1943).

$v_{e}=\frac{\ln \left(1-V_{r}\right)+V_{r}+\mu V_{r}^{2}}{V_{0}\left(V_{r}^{\frac{1}{3}}-\frac{V_{r}}{2}\right)}$

where: $v_{\mathrm{e}}$ - the crosslink density $\left(\mathrm{mol} / \mathrm{cm}^{3}\right) ; \mathrm{V}_{0}$ - the molecular volume of solvent $\left(106.7 \mathrm{~cm}^{3} / \mathrm{mol}\right) ; \mu$-the Huggins parameter of the NR-solvent interaction was calculated from the equation $\mu=0.478+0.228 \mathrm{~V}_{\mathrm{r}}$, where $\mathrm{V}_{\mathrm{r}}$ is the volume fraction of elastomer in the swollen gel (Eq. 2).

$\mathrm{V}_{\mathrm{r}}=\frac{1}{1+\mathrm{Q}_{\mathrm{w}} \frac{\rho_{\mathrm{r}}}{\rho_{\mathrm{s}}}}$

where: Qw-equilibrium swelling reduced by the filler content $(\mathrm{x}$ [phr] $)-\mathrm{Qw}=(100+\mathrm{x} / 100) ; \rho_{\mathrm{r}}$-density of rubber $\left[\mathrm{g} / \mathrm{cm}^{3}\right]\left(0.99 \mathrm{~g} / \mathrm{cm}^{3}\right) ; \rho_{\mathrm{s}}$-density of solvent $\left[\mathrm{g} / \mathrm{cm}^{3}\right]\left(0.86 \mathrm{~g} / \mathrm{cm}^{3}\right)$.

Mechanical properties of composites were measured by using an universal machine (Zwick, Ulm, Germany). Tensile strength was determined in accordance with standard ISO 37 by using standard dumbbell-shaped samples. The samples were subjected to a stress-strain test at a cross-head speed $500 \mathrm{~mm} / \mathrm{min}$. The measurements were performed at room temperature. From the obtained stress-strain curve, tensile strength (TS), elongation at break (Eb), and modulus (SE) were determined. Obtained results from the 5 specimens for each composite were averaged.

Hardness of vulcanizates was determined according to ISO 868 standard using a Shore type A Durometer (Zwick/Roell, Ulm, Germany) and showed results are average from random ten points for each sample.

The relative damping of composites was measured according to the PN-C-04289 standard by using disc shape of the samples. Dimensions of specimens: diameter $-35 \mathrm{~mm}$ and height $-17.8 \mathrm{~mm}$. The analysis was carried out at room temperature by using an universal machine (Zwick, Ulm, Germany). Each sample was stressed from 0 to $0.7 \mathrm{MPa}$ and then stress was reduced. Hysteresis loops were recorded and the relative damping values were determined according to the Eq. 3:

$\mathrm{T}_{\tau \mathrm{w}}=\frac{\Delta \mathrm{W}_{\mathrm{i}}}{\Delta \mathrm{W}_{\mathrm{ibel}}} \cdot 100 \%$

where: $\mathrm{T}_{\tau \mathrm{w}}$-relative damping, $\Delta \mathrm{W}_{\mathrm{i}}$ - the difference between the compression work and the work during reducing the compressive stresses, $\mathrm{W}_{\text {ibel_compres- }}$ sion work.

Dynamic mechanical analysis (DMA) were performed with the application of ARES Rheometer (plate-plate system, plate diameter: $20 \mathrm{~mm}$; gap $2 \mathrm{~mm}$ ). DMA test parameters: temperature: $25^{\circ} \mathrm{C}$, sample deformation rate: $10 \mathrm{rad} / \mathrm{s}$, stress: from 0.1 to $100 \%$, test force: $5 \mathrm{~N}$. The Payne effect $\left(\Delta \mathrm{G}^{\prime}\right)$ values of the composites have been calculated based on the Eq. 4.

$\Delta \mathrm{G}^{\prime}=\mathrm{G}_{\min }^{\prime}\left(\lim 10^{-1}\right)-\mathrm{G}_{\max }^{\prime}(\infty)$

where: $\mathrm{G}_{\text {min }}^{\prime}\left(\lim 10^{-1}\right)$ - a composite storage modulus determined under the deformation of $10^{-1} \%$; $\mathrm{G}_{\text {min }}^{\prime}(\infty)$ - a composite storage modulus determined under the maximum deformation.

The thermo-oxidative degradation of the vulcanizates was performed at a temperature of $70{ }^{\circ} \mathrm{C}$ for 14 days. To estimate the resistance of the samples to aging, their mechanical properties after aging were determined and compared with the values obtained for vulcanizates before the aging process. The aging factor $(\mathrm{K})$ was calculated as the numerical change in the mechanical properties of the samples upon aging (Eq. 5) (Masek et al. 2012):

$\mathrm{K}=\left(\mathrm{TS} \cdot \mathrm{E}_{\mathrm{b}}\right)_{\text {afteraging }} /\left(\mathrm{TS} \cdot \mathrm{E}_{\mathrm{b}}\right)_{\text {beforeaging }}$

where: TS is the tensile strength of the vulcanizate, and EB is the elongation at break.

The flammability of vulcanizates was studied by the method of oxygen index (OI) using $50 \times 10 \times 4 \mathrm{~mm}$ samples, at a constant nitrogen flow rate in a measurement column $(\mathrm{D}=75 \mathrm{~mm})$ amounting to $40 \pm 2 \mathrm{~mm} \times \mathrm{s}^{-1}$. The concentration of oxygen was selected so that the sample could be completely 
burned within $180 \mathrm{~s}$. The sample tip was ignited for $5 \mathrm{~s}$ by means of a gas burner supplied with propanebutane mixture. The value of OI was calculated from the following Eq. (6):

$\mathrm{OI}=\frac{\left[\mathrm{O}_{2}\right]}{\left[\mathrm{O}_{2}\right]+\left[\mathrm{N}_{2}\right]} \cdot 100 \%$

where: $\left[\mathrm{O}_{2}\right]$ is the final flow rate of oxygen, at which a sample is burned within $180 \mathrm{~s}[\mathrm{l} / \mathrm{h}] ;\left[\mathrm{N}_{2}\right]$ is a constant flow rate of nitrogen $[1 / \mathrm{h}]$.

Barrier properties were evaluated based on the through-plane air permeability of composites using manometric method in accordance with the ASTM D1434 standard. The tests were conducted by using atmospheric air at room temperature. Measurement of the barrier properties was based on a pressure difference in the chambers on both sides of the sample.

The barrier properties was determined by gas transmission rate (GTR) and coefficient of gas permeability $(\mathrm{P})$, that were calculated from the following Eqs. (7), (8):

$\mathrm{GTR}=\frac{\mathrm{V}_{\mathrm{c}}}{\mathrm{R} \cdot \mathrm{T} \cdot \mathrm{P}_{\mathrm{u}} \cdot \mathrm{A}} \cdot \frac{\mathrm{dp}}{\mathrm{dt}}$

$\mathrm{P}=\mathrm{GTR} \cdot \mathrm{d}$

where: $\mathrm{d}$-the thickness of the sample $[\mathrm{m}] ; \mathrm{V}_{\mathrm{c}}-$ volume of low-pressure chamber [1]; T-temperature $[\mathrm{K}] ; \mathrm{P}_{\mathrm{u}}$ - the gas pressure in the high-pressure chamber $[\mathrm{Pa}]$; $\mathrm{A}$-area permeation of gas through the sample $\left[\mathrm{m}^{2}\right]$; dp/dt-pressure changes per unit time $[\mathrm{Pa} / \mathrm{s}] ; \mathrm{R}$-gas constant $8.31 \cdot 10^{3}[(\mathrm{~Pa}) /(\mathrm{K} \mathrm{mol})]$.

The morphology of the composites surface and the dispersion of the filler were evaluated by means of Scanning Electron Microscopy with field emission (Hitachi, TM-1000, Tokio Japan). Before the SEM measurements, the samples were placed on carbon plasters and coated with the use of carbon target by the Cressington 208 HR system. The accelerating voltage was $25 \mathrm{kV}$.

\section{Results and discussion}

Scanning electron microscopy analysis

In order to assess the influence of the shape and size of solid phase particles on the macroscopic properties of composite samples, scanning electron microscopy images (SEM) of used fillers and composites were prepared and studied (Figs. 2, 3).

Both modified and unmodified fillers exhibit inhomogeneity in shape and particle size. Their size ranges from a dozen to several dozen microns. Varied morphology of used fillers could be related to the efficiency of the milling processes. The type of filler (particle shape, particle size, specific surface area, concentration of disperse phase) effects on the multifunction properties of composites. Non-homogeneous structure of the filler particles can result differentiation of properties and incomplete exploitation of the reinforcing potential of the dispersed phase.

Analyzing the presented SEM photographs of selected composites (10 phr), no significant effect of straw silanization on the improvement of the degree of dispersion in natural rubber was observed. Both materials were characterized by good dispersed filler in the elastomer. There are straw particles of various sizes present in the matrix, which is related to the heterogeneous characteristics of the filler used. The continuous morphology of composite indicate that the cereal straw is well connected to the elastomeric matrix. The proper distribution of the filler particles has a significant impact on its reinforcing effect, and thus the mechanical properties of the vulcanizates.

\section{Thermal analysis}

The thermal properties of straw (unmodified and silanized) were determined by means of thermogravimetric analysis. Based on the obtained data, the influence of straw modification on thermal decomposition of lignocellulosic material (Fig. 4) was described. The curves represent the mass loss (TG curve) and mass loss rate (DTG curve) of both types of tested fibers.

Thermal decomposition of straw occurred in two stages, which is reflected by two peaks on the DTG curve. The differences visible in the first step of the decomposition were related to the loss of water content in the samples, which resulted in a slight loss of mass. The loss of mass due to the evaporation of moisture contained in the unmodified fiber was greater than in the case of a silanized straw. The silane treatment may have contributed to reducing the hygroscopicity of the material.

The next stage was related to the degradation of the lignocellulosic material. The process can be divided 

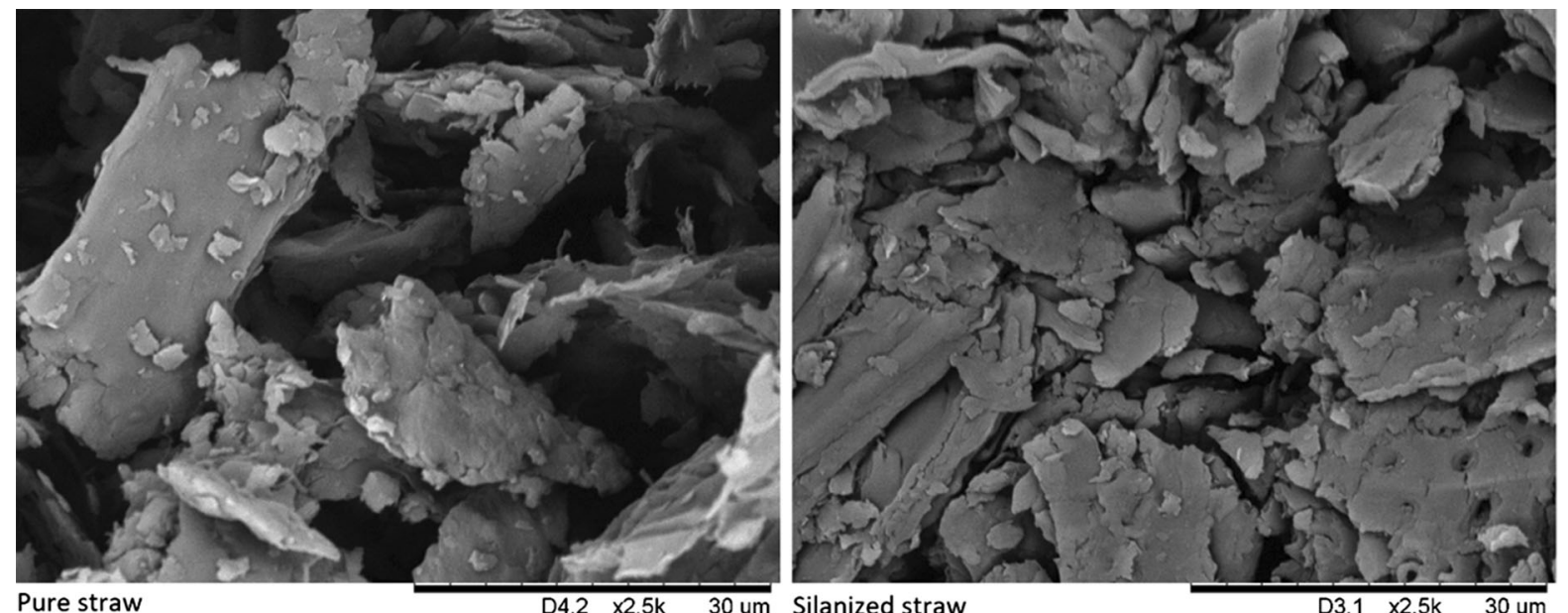

Fig. 2 SEM images of pure straw (left) and silanized straw (right) (the magnification: $\times 2500$ )
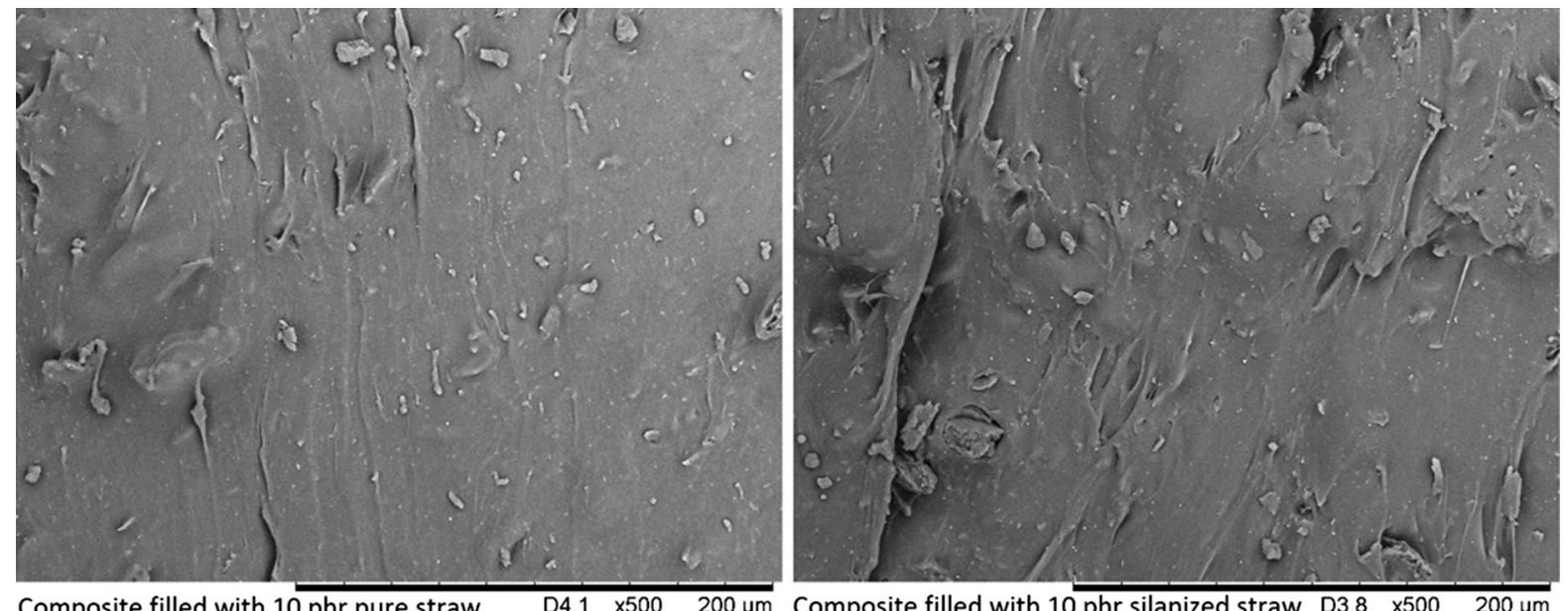

Composite filled with $10 \mathrm{phr}$ pure straw

$\mathrm{D} 4,1 \times 500$

Composite filled with $10 \mathrm{phr}$ silanized straw $\quad \mathrm{D} 3,8 \quad \times 500$

Fig. 3 SEM images of composites containing $10 \mathrm{phr}$ pure (left) and silanized straw (right) (the magnification: $\times 500$ )

into main steps: degradation of hemicellulose (220-315 $\left.{ }^{\circ} \mathrm{C}\right)$; lignin and cellulose decomposition $\left(315-400{ }^{\circ} \mathrm{C}\right)$ and lignin degradation $\left(>450{ }^{\circ} \mathrm{C}\right)$ (Asadieraghi and Wan Daud 2014). DTG curve shows the speed of mass loss during thermogravimetric measurements. Silanization of straw has improved its thermal properties compared to unmodified fibers. Silanized straw also showed a lower rate of weight loss than unmodified fibers. The temperatures of the 5, 10, $50 \%$ weight loss for the unmodified fibers were 130 , 253 and $329{ }^{\circ} \mathrm{C}$, respectively, whereas for silanized straw fibers the temperatures were higher and amounted to 187,261 and $345^{\circ} \mathrm{C}$.

\section{FTIR analysis}

Modification by silanization is effective in removal of large amounts of lignin and hemicelluloses, which is indicated by reduction in intensity of the peak at $1250 \mathrm{~cm}^{-1}$, and around $1600-1650 \mathrm{~cm}^{-1}$ (Fig. 5). Silane treatment reduces pectin and wax, at the peak around $1750 \mathrm{~cm}^{-1}$. The presence of the peak around $1100 \mathrm{~cm}^{-1}$ in silane treated fibres is due to the formation of asymmetric stretching vibrations of $\mathrm{Si}-$ $\mathrm{O}-\mathrm{Si}$ and $\mathrm{Si}-\mathrm{O}-\mathrm{C}$ bonds, which indicate the reaction between silane and the fibres and the presence of a polysiloxane network. The vibration peak present at $805 \mathrm{~cm}^{-1}$ due to $\mathrm{Si}-\mathrm{C}$ stretching bond revealed silane 
Fig. 4 TG and DTG curves of pure and silanized straw
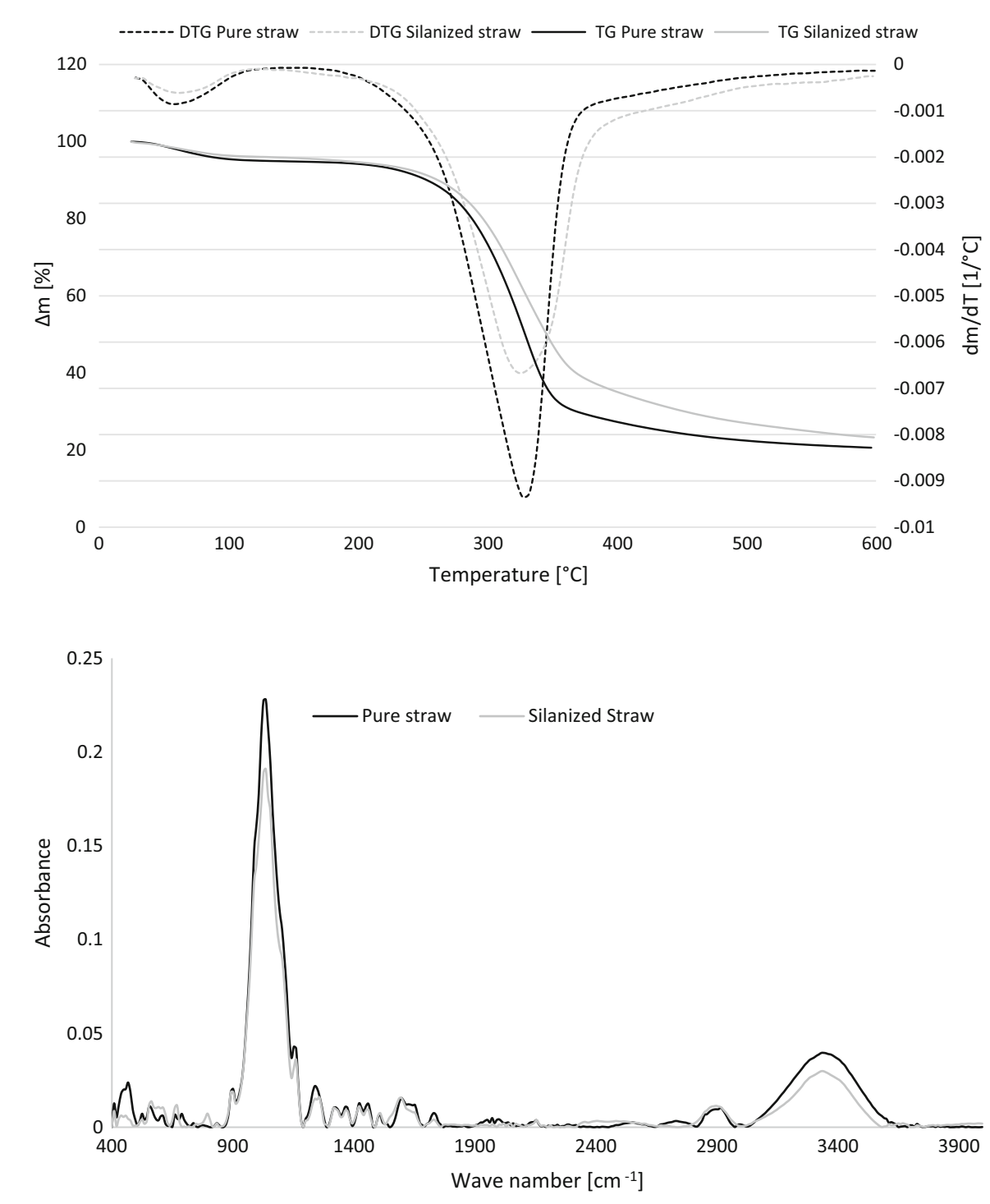

Fig. 5 FTIR spectra of pure and silanized straw presence on the straw surface. This was an indication of very good interfacial interaction between the silane coupling agent and the surface of the lignocellulose materials (Asim et al. 2016).

\section{Contact angle}

The contact angles between water and the pressed surfaces of unmodified and silanized straw are shown in Fig. 6. When the droplet was placed on the straw surface, the more hydrophilic nature showed pure straw, since the contact angle between the surfaces was about $74^{\circ}$. In the case of silanized straw, this angle was almost twice as large and amounted to $133^{\circ}$. On the surface of the samples, the drop of water spread over time, the drop was soaked. The difference during the disappearance of the drop was significant. The time of absorption of the drop on the surface of sialinated straw was much longer and occurred after $15 \mathrm{~s}$, while on the surface of pure straw the drop disappeared after $0.5 \mathrm{~s}$. The results indicate that the silanized straw fibers were characterized by reduced hydrophilicity. This could contribute to greater compatibility of silanized straw and natural rubber, which in turn will affect the stronger connection and adhesion between components of the composite. 


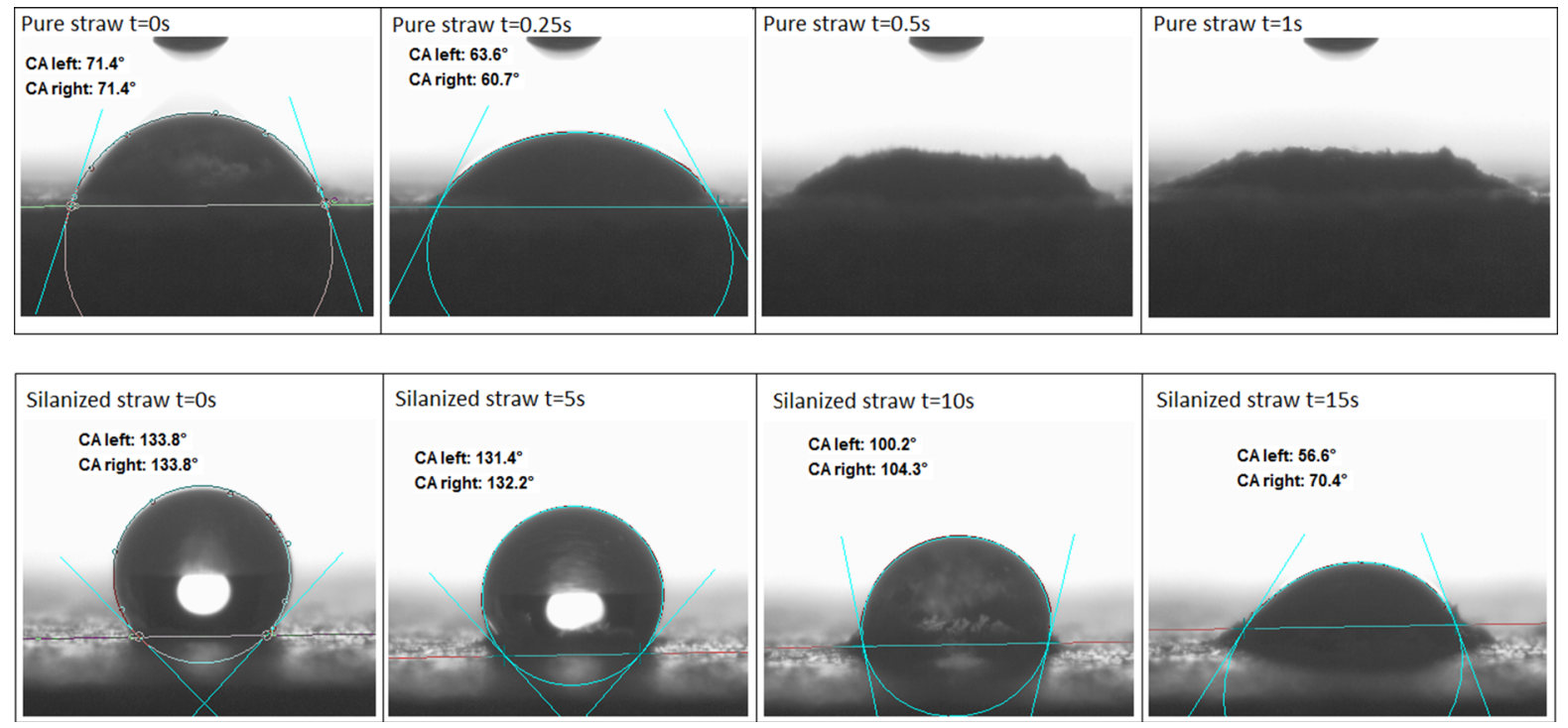

Fig. 6 Images of drops on the surface of pure and silanized straw in time

Rheometric properties and crosslinking density

The vulcanization time $\left(\mathrm{t}_{90}\right)$, scorch time $\left(\mathrm{t}_{\mathrm{s} 2}\right)$, also minimum $\left(\mathrm{M}_{\min }\right)$ and maximum $\left(\mathrm{M}_{\max }\right)$ torque gain values obtained in rheometry measurements of rubber mixtures filled with pure and silanized straw are shown in Table 2.

The results indicated that the time of crosslinking and the scorch time of natural rubber slightly decreased after introducing the filler into the polymer medium. Silanization had no considerable effect on the vulcanization prosses.

The increase in the maximum torque with the higher content of straw indicates that the presence of straw in the polymer medium has reduced the mobility of the macromolecule chains. Both untreated and silanized straw showed an upward trend. However, the modified filler exhibited a higher level of torque gain compared to untreated straw. This was most likely related to the creation of a more extensive structure of the spatial network. The results confirmed that the addition of the filler and the increase in its content influenced the increase in the vulcanizates crosslinking density (Fig. 7), and consequently the increase in torque during vulcanization. The use of silanized straw as a filler caused a further increase in the torque gain during the vulcanization process due to the increase in the crosslinking density of the vulcanizate.

Changes in the values of $\Delta \mathrm{M}$ affected by the presence of fillers' structure in elastomer matrix are an indirect measure of the hydrodynamic effect. This effect is related to addition of a non-deformable phase

Table 2 Rheometric properties and vulcanization parameters of elastomer mixtures

\begin{tabular}{|c|c|c|c|c|c|c|}
\hline & Content of filler & $\mathrm{M}_{\min }[\mathrm{dNm}]$ & $\mathrm{M}_{\max }[\mathrm{dNm}]$ & $\Delta \mathrm{M}[\mathrm{dNm}]$ & $\mathrm{t}_{\mathrm{s} 2}[\mathrm{~min}]$ & $\mathrm{t}_{90}[\mathrm{~min}]$ \\
\hline Reference sample & 0 & 0.6 & 5.71 & 5.11 & 0.51 & 2.87 \\
\hline \multirow[t]{3}{*}{ Pure straw } & 10 & 0.65 & 6.1 & 5.45 & 0.48 & 1.98 \\
\hline & 20 & 0.78 & 7.16 & 6.38 & 0.46 & 2.01 \\
\hline & 30 & 0.85 & 8.07 & 7.22 & 0.48 & 2.08 \\
\hline \multirow[t]{3}{*}{ Silanized straw } & 10 & 0.72 & 6.63 & 5.91 & 0.43 & 1.92 \\
\hline & 20 & 1.02 & 8.47 & 7.45 & 0.43 & 1.98 \\
\hline & 30 & 1.07 & 9.45 & 8.38 & 0.44 & 2.1 \\
\hline
\end{tabular}


Fig. 7 Impact of straw modifications and the fillers content on the crosslinking density of biocomposites

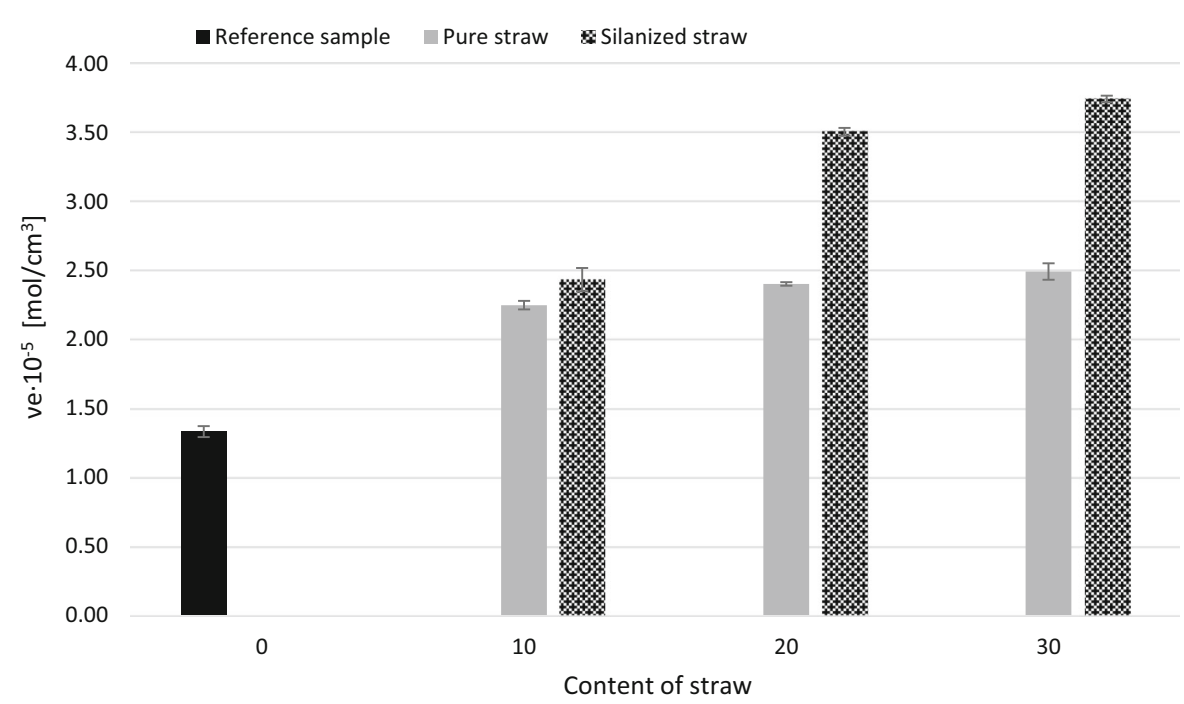

to the polymer matrix, which can manifest itself by improving the mechanical properties of the composites. Also the increase of the rheometric torque gain probably resulted from the increment of biocomposites cross-link density. The increasing fillers loading resulted in the increase of crosslink density. Fillerpolymer interactions behave like physical network nodes and act as additional elements in the system's network. As a result of the increase in the overall crosslink density due to the presence of the filler in the polymer, the strength of the network, as a consequence, also the stiffness of the composites increases with the increase of the filler-polymer interactions.

\section{Mechanical properties}

Achieving greater compatibility between the elastomeric matrix and filler particles through the modification process resulted in the expected improvement in the tensile strength of the vulcanizates. Such changes were probably possible due to the increase in interactions at the interface between rubber and silanized straw, which was reflected in the increase in cross-linking density. The largest reinforcing effect was observed for samples containing 10 and $20 \mathrm{phr}$ of silanized straw. A further increase in content up to $30 \mathrm{phr}$ caused a slight decrease in the TS value, however not below the reference system (Fig. 8). This may have resulted from a significant increase in the cross-link density, and consequently also in larger modules at 100, 200 and 300\% elongation and a reduction in elongation at break (Table 3). The research also confirmed that the introduction of straw into the rubber (regardless of its modification) contributes to the increase in the hardness of the composites relative to the reference sample. The hardness values obtained were the higher, the higher the proportion of filler in the composites.

The full mechanical characteristics of rubber is obtained as a result of the evaluation of its dynamic properties, at a given temperature and constant deformation frequency, uniquely determined by the dynamic module (Fig. 9) and angle of the phase shift$\tan \delta$ (Fig. 10). The rubber properties are strongly nonlinear, hence the values of the modules strongly depend on both the temperature and the size of the deformation as well as its frequency.

The addition of the filler to the elastomeric medium causes an increase in the elastic modulus $\mathrm{G}^{\prime}$, which is caused by the creation of its own structure by the filler, the so-called "network" in the elastomer. The dynamic module of vulcanizates filled with straw decreases as the deformation amplitude increases, which is the result of breaking the interactionsmainly van der Waals and hydrogen bonds between aggregates. This phenomenon has been thoroughly examined in the works of A. R. Payne and M.-J. Wanga (Payne 1965; Wang 1998).

The increase in modulus, especially in the small deformation range (Fig. 9) of vulcanizates containing a silanized filler compared to composites filled with pure straw, could indicate the formation of a more 
Fig. 8 Effects of straw filler type and content on tensile strength of the vulcanizates

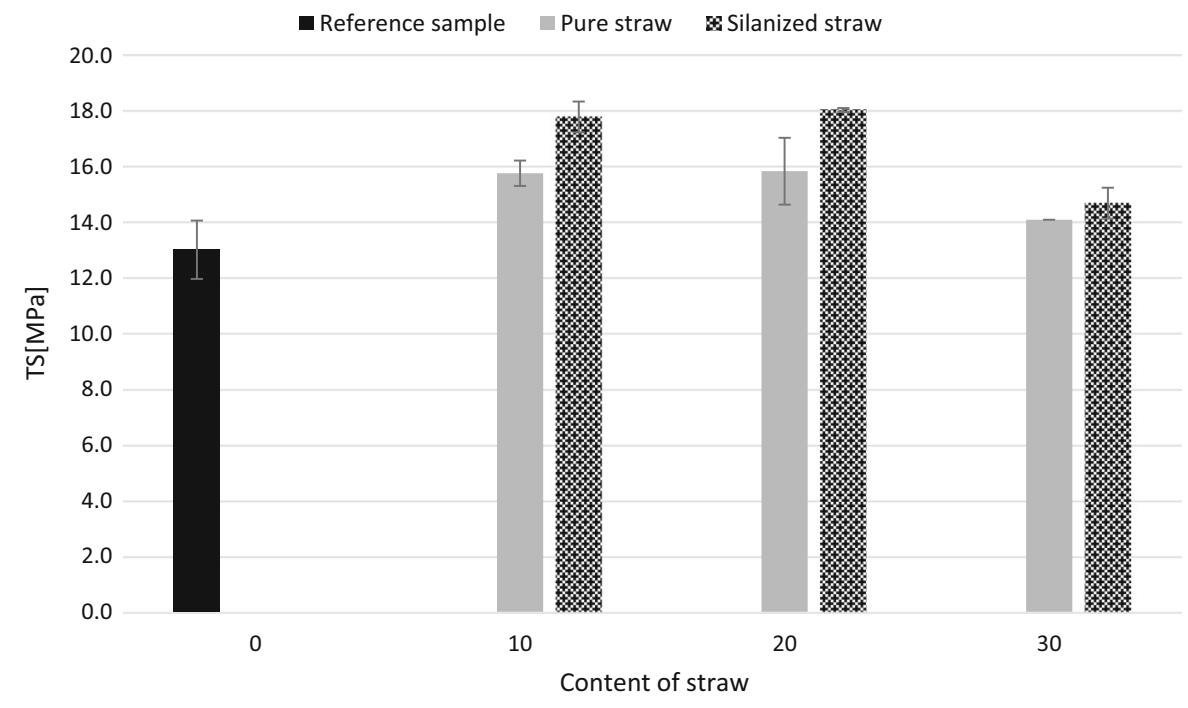

Table 3 Influence of different straw fillers content on the mechanical properties and hardness of the vulcanizates

\begin{tabular}{lcccccc}
\hline & Content of filler & $\mathrm{SE}_{100}[\mathrm{MPa}]$ & $\mathrm{SE}_{200}[\mathrm{MPa}]$ & $\mathrm{SE}_{300}[\mathrm{MPa}]$ & $\mathrm{Eb}[\%]$ & Hardness $\left[{ }^{\circ} \mathrm{Sh} \mathrm{A}\right]$ \\
\hline Reference sample & 0 & $0.78 \pm 0.03$ & $1.21 \pm 0.03$ & $1.85 \pm 0.05$ & $560 \pm 34$ & $26.4 \pm 0.5$ \\
Pure straw & 10 & $1.26 \pm 0.21$ & $2.04 \pm 0.33$ & $4.34 \pm 0.95$ & $445 \pm 53$ & $33.9 \pm 0.9$ \\
& 20 & $1.83 \pm 0.24$ & $2.87 \pm 0.39$ & $5.75 \pm 0.32$ & $430 \pm 38$ & $37.6 \pm 0.3$ \\
& 30 & $2.36 \pm 0.01$ & $4.18 \pm 0.64$ & $7.4 \pm 0.35$ & $489 \pm 25$ & $45.0 \pm 0.5$ \\
Silanized straw & 10 & $1.52 \pm 0.06$ & $2.78 \pm 0.09$ & $4.53 \pm 0.20$ & $532 \pm 16$ & $33.1 \pm 1.1$ \\
& 20 & $2.31 \pm 0.06$ & $4.32 \pm 0.05$ & $7.51 \pm 0.11$ & $509 \pm 4$ & $41.0 \pm 0.4$ \\
& 30 & $4.51 \pm 0.38$ & $10.47 \pm 0.45$ & $10.25 \pm 0.13$ & $357 \pm 33$ & $42.0 \pm 0.6$ \\
\hline
\end{tabular}

Fig. 9 Storage modulus of biocomposites filled with straw as a function of oscylation strain

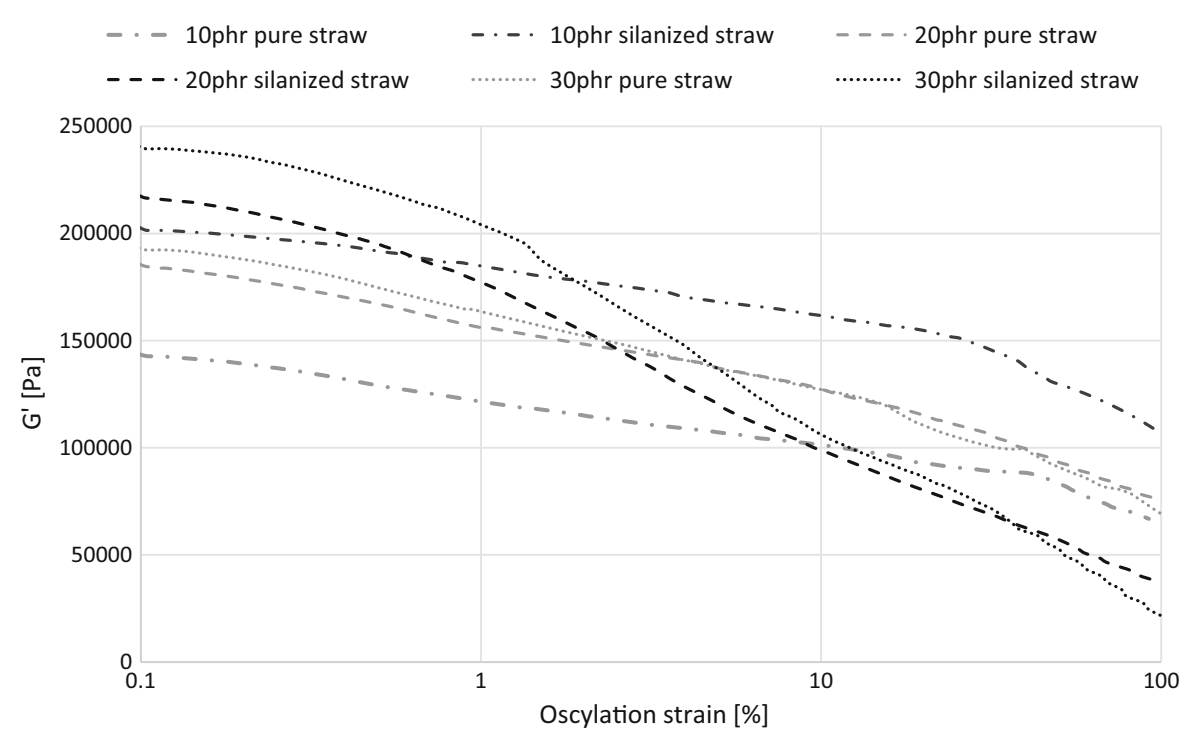


Fig. $10 \operatorname{Tan} \delta$ of biocomposites filled with straw as a function of oscylation strain

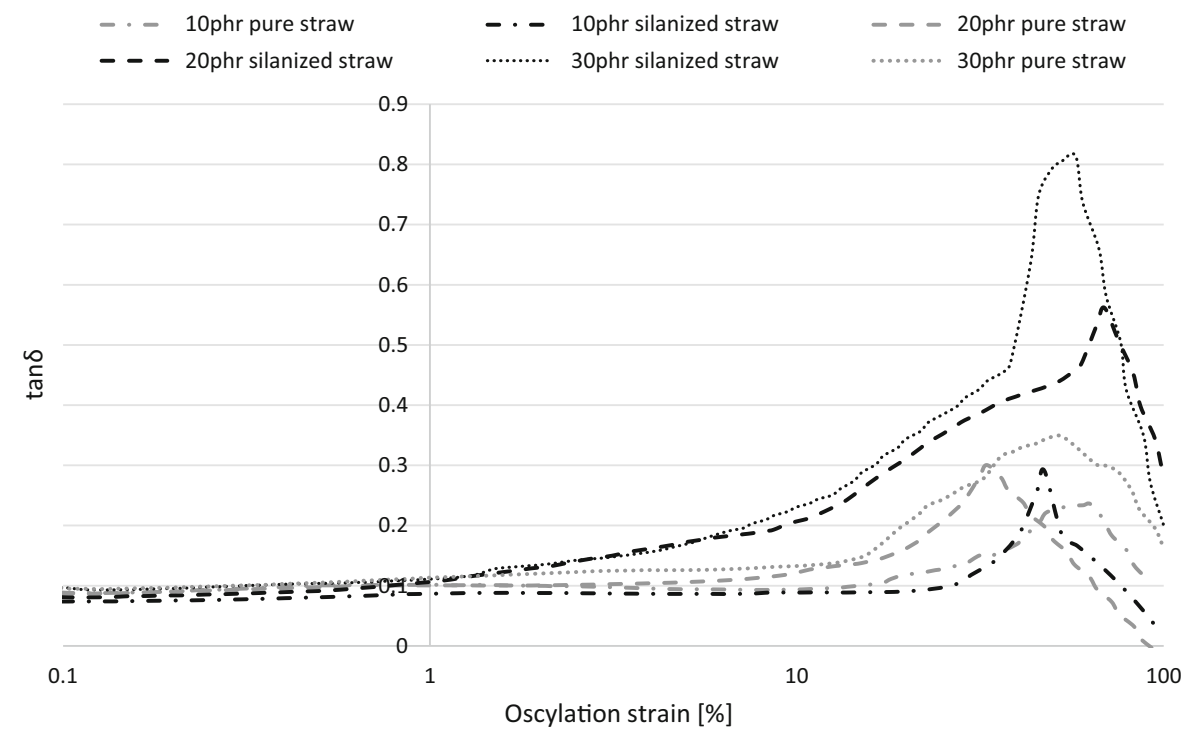

extensive and developed filler-filler network. The fact that the composites showed a larger G 'modulus at small strain amplitudes proved that the straw particles showed a stronger tendency to mutual interactions in the elastomeric medium, as well as a greater tendency for agglomeration, rather than filler-polymer interactions.

The decrease in the storage module (Payne effect) in the whole strain range numerically expressed as $\Delta \mathrm{G}^{\prime}$ (Table 4) also confirmed greater activity of the modified straw. In all cases, an increase in $\Delta \mathrm{G}^{\prime}$ values was observed for composites containing a silanized filler. This effect is the more pronounced the higher the content of the filler in the composition. It means that the structure created by its particles has become more developed, and thus the scale of filler-filler interactions that are damaged during sample deformation has increased.

The maximum $\tan \delta$ loss angle (Fig. 10) is in the area of strain amplitude, in which the fastest dynamic

Table 4 Payne effect values of biocomposites filled with straw (pure and silanized)

\begin{tabular}{lll}
\hline Content of straw & $\begin{array}{l}\text { Pure straw } \\
\Delta \mathrm{G}^{\prime}[\mathrm{MPa}]\end{array}$ & Silanized straw \\
\hline 10 & 0.08 & 0.09 \\
20 & 0.11 & 0.18 \\
30 & 0.13 & 0.22 \\
\hline
\end{tabular}

module decrease is observed, so additional mechanical energy dissipation is associated with disruption of physical bonds both filler-filler and filler-elastomer. It is known that the higher the angle of the tested material, the greater is the damping of mechanical vibrations and greater dissipation of mechanical energy. Increasing the filler content in vulcanizates caused a significant increase in the loss angle value almost in the entire range of strain amplitudes, which led to a decrease in elasticity and thus an increase in damping properties of the composites. The improvement of the quality of the natural-straw rubber connection by silanization of the filler positively influenced the attenuation characteristics.

Good damping properties of composites were also confirmed by tests of damping coefficient under compressive stress conditions. The vibration damping coefficient is a measure of the material's ability to absorb the vibration energy of the element subjected to a cyclic load. The addition of straw resulted in the improvement of the damping properties of the composites produced, which indicates an increase in their ability to dissipate energy during deformation (Fig. 11). With the increase in its content, the relative attenuation values $\mathrm{T} \tau \mathrm{w}$ have increased, reaching at $30 \mathrm{phr}$ twice the value of the unfilled system. The damping occurring at the interface between the matrix and the dispersed phase (interface damping) is related to, inter alia, the quality of their connection. Both weak and very good adhesion can potentially improve 


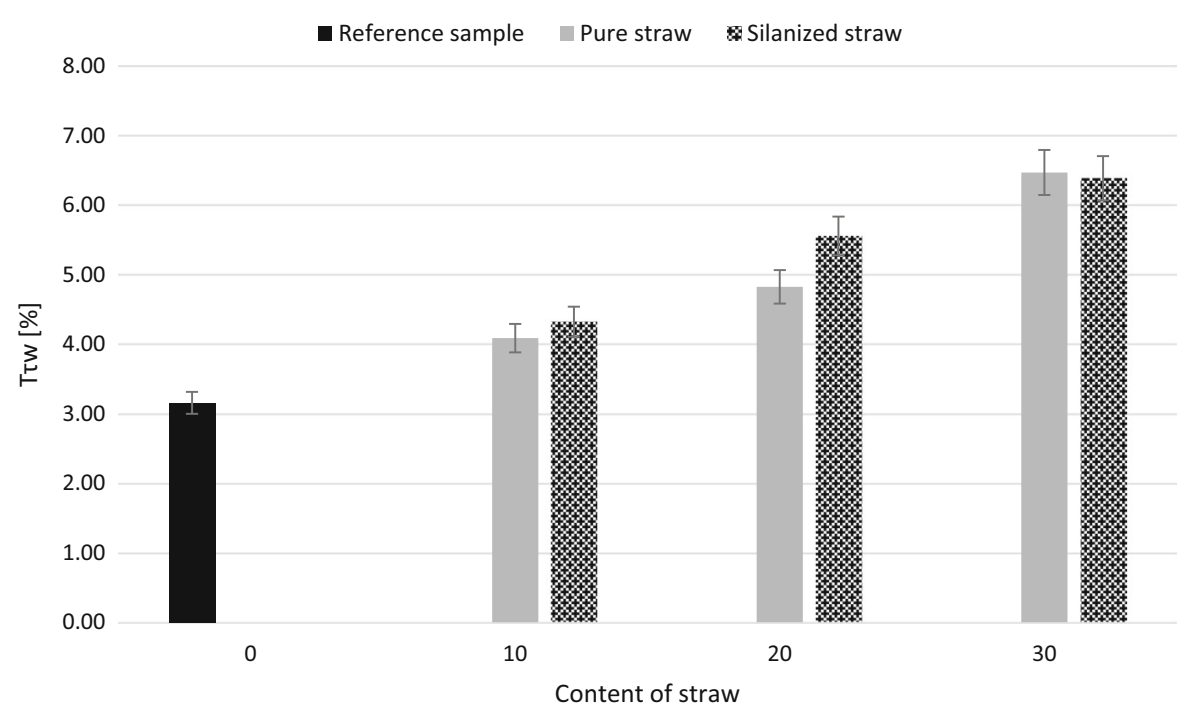

Fig. 11 Influence of different straw fillers content on the damping of the biocomposites

the composite's ability to dampen vibrations. The use of the straw silanization process to increase compatibility and improve interfacial adhesion has increased the ability to dissipate the energy of composites filled with it.

\section{Barrier properties}

The obtained composites showed an improvement in barrier properties (Table 5). The reduction in gas permeability may have resulted from the method of distribution of the straw particles in the polymer matrix. Due to their complex, fiber-like structure, particles can form layers, making it difficult to diffuse air between successive batches of filler. Vulcanizates containing silanized straw were characterized by much more limited gas permeability compared to samples with pure cereal straw. A significant decrease in the $P$ value compared to the unfilled system was already observed at $10 \mathrm{phr}$. In the case of pure straw vulcanizates, a similar $\mathrm{P}$ value was obtained for a composite filled with 30 parts by weight. Silane straw compatibilization for better interfacial connection with the elastomer probably reduced the mobility of the polymer chain, which hindered the penetration of air through the modified vulcanizate surface.

\section{Flamability}

Straw as a flammable material supports the burning of vulcanizates filled with it, as evidenced by the decrease in the oxygen index for composites compared to the reference sample (Fig. 12). The flammability of the materials increased as the straw content increased.

Table 5 Gas transmission rate (GTR) and coefficient of gas permeability (P) of rubber composities

\begin{tabular}{llll}
\hline & Content of filler & GTR $\cdot 10^{-7}\left[\mathrm{~mol} /\left(\mathrm{m}^{2} \cdot \mathrm{s} \cdot \mathrm{Pa}\right)\right]$ & $\mathrm{P} \cdot 10^{-10}[\mathrm{~mol} /(\mathrm{m} \cdot \mathrm{s} \cdot \mathrm{Pa})]$ \\
\hline Reference sample & 0 & 2.12 & 3.28 \\
Pure straw & 10 & 2.98 & 3.04 \\
& 20 & 1.79 & 1.79 \\
Silanized straw & 30 & 0.63 & 0.60 \\
& 10 & 0.87 & 0.79 \\
& 20 & 0.63 & 0.67 \\
\end{tabular}


Fig. 12 The oxygen index values of natural rubber vulcanizates

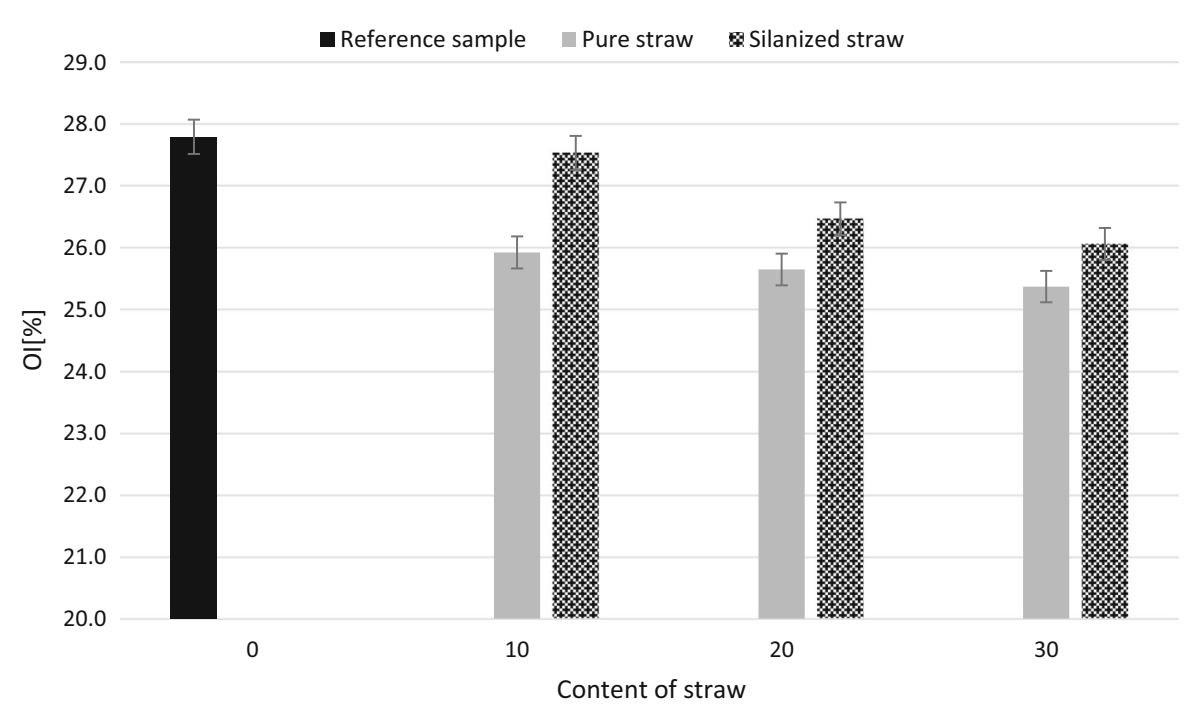

A slight increase in IO was observed for all composites prepared using modified cereal straw. Silanes acting as coupling agents can bind the fillers and polymer matrix very easily with little energy by simple synthetic rout, with moreover a great contribution to forming a compact and dense char layer during combustion (Shah et al. 2017).

\section{Thermo-oxidative aging}

The resistance to thermo-oxidative aging was evaluated on the basis of changes in mechanical properties of vulcanizates before and after the simulation of aging processes at elevated temperature with air access (Fig. 13). The thermo-oxidation aging factor obtained for vulcanizates of pure natural rubber was 0.64. On this basis, it was found that the mechanical properties of these samples deteriorated as a result of the thermo-oxidative aging process. The poor resistance of the elastomer to aging is related to its structure, because the poly-isoprene molecule has unsaturated bonds that are active in the degradation process. The obtained results showed that even the smallest straw addition improved the resistance of composites to thermo-oxidative aging. Regardless of the type and amount of introduced filler, the aging coefficients obtained for the composites filled with it were higher than the reference sample, however the values varied. It proves that their mechanical properties have not changed as much as unfilled natural rubber. This effect is most likely caused by the presence of lignin in the straw. Lignin contains phenolic hydroxyl group that also has a strong antioxidant function.

\section{Conclusions}

Silanization process influenced the physico-chemical characteristics of the cereal straw which was reflected by:

- improving the thermal stability of the fibers and reducing the rate of weight loss compared to the unmodified filler;

- reduction of large amounts of lignin and hemicellulose, reduction of waxes and pectins and introduction of silane on the fiber surface;

- increased hydrophobicity of the lignocellulosic material.

As a result of the filler-elastomer interface interactions increment, the carried out modification has also significantly influenced the characteristics of natural rubber composites, changing a number of its functional properties:

- improvement of rheometric properties and crosslinking density as an increase of torque gain during vulcanization;

- higher values of tensile strength and hardness;

- increase in damping and barrier properties;

- reduction of flammability and tendency to undergo thermo-oxidative aging processes. 


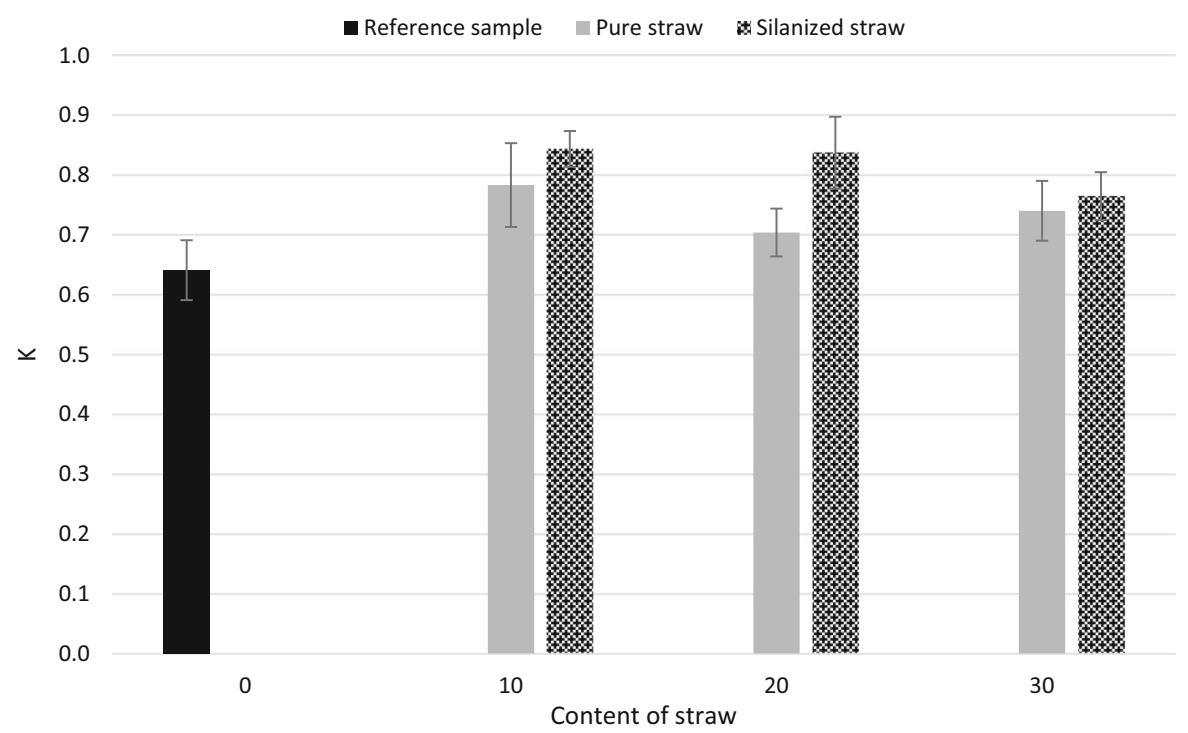

Fig. 13 Thermal aging factor of reference sample and biocomposities filled with pure or silanized straw (10-30 phr)

Open Access This article is distributed under the terms of the Creative Commons Attribution 4.0 International License (http:// creativecommons.org/licenses/by/4.0/), which permits unrestricted use, distribution, and reproduction in any medium, provided you give appropriate credit to the original author(s) and the source, provide a link to the Creative Commons license, and indicate if changes were made.

\section{References}

Asadieraghi M, Wan Daud WMA (2014) Characterization of lignocellulosic biomass thermal degradation and physiochemical structure: effects of demineralization by diverse acid solutions. Energy Convers Manag 82:71-82. https:// doi.org/10.1016/j.enconman.2014.03.007

Asim M, Jawaid M, Abdan K, Ishak MR (2016) Effect of alkali and silane treatments on mechanical and fibre-matrix bond strength of kenaf and pineapple leaf fibres. J Bionic Eng 13:426-435. https://doi.org/10.1016/S1672-6529(16)60315-3

Bledzki AK, Mamun AA, Lucka-Gabor M, Gutowski VS (2008) The effects of acetylation on properties of flax fibre and its polypropylene composites. Express Polym Lett 2:413-422. https://doi.org/10.3144/expresspolymlett.2008.50

Chun KS, Husseinsyah S (2014) Polylactic acid/corn cob ecocomposites: effect of new organic coupling agent. J Thermoplast Compos Mater 27:1667-1678. https://doi.org/10. 1177/0892705712475008

Chun KS, Husseinsyah S, Azizi FN (2013) Characterization and properties of recycled polypropylene/coconut shell powder composites: effect of sodium dodecyl sulfate modification. Polym Plast Technol Eng 52:287-294. https://doi.org/10. 1080/03602559.2012.749282

Deng Y, Paraskevas D, Tian Y et al (2016) Life cycle assessment of flax-fibre reinforced epoxidized linseed oil composite with a flame retardant for electronic applications. J Clean Prod 133:427-438. https://doi.org/10.1016/j. jclepro.2016.05.172

Dhakal HN, Sarasini F, Santulli C et al (2015) Effect of basalt fibre hybridisation on post-impact mechanical behaviour of hemp fibre reinforced composites. Compos Part A Appl Sci Manuf 75:54-67. https://doi.org/10.1016/j.compositesa. 2015.04.020

Eqra N, Ajabshirchi Y, Sarshar M (2014) Effect of ozonolysis pretreatment on enzymatic digestibility of sugarcane bagasse. Agric Eng Int CIGR J 16:151-156. https://doi.org/ 10.1016/j.biortech.2008.09.012

Flory PJ, Rehner J (1943) Statistical mechanics of cross-linked polymer networks I. Rubberlike elasticity. J Chem Phys 11:512-520. https://doi.org/10.1063/1.1723791

Gámez S, González-Cabriales JJ, Ramírez JA et al (2006) Study of the hydrolysis of sugar cane bagasse using phosphoric acid. J Food Eng 74:78-88. https://doi.org/10.1016/j. jfoodeng.2005.02.005

Heggset EB, Syverud K, Øyaas K (2016) Novel pretreatment pathways for dissolution of lignocellulosic biomass based on ionic liquid and low temperature alkaline treatment. Biomass Bioenergy 93:194-200. https://doi.org/10.1016/j. biombioe.2016.07.023

Kabir MM, Wang H, Lau KT, Cardona F (2012) Chemical treatments on plant-based natural fibre reinforced polymer composites: an overview. Compos Part B Eng 43:2883-2892. https://doi.org/10.1016/j.compositesb.2012.04.053

Kalaprasad G, Francis B, Thomas S et al (2004) Effect of fibre length and chemical modifications on the tensile properties of intimately mixed short sisal/glass hybrid fibre reinforced low density polyethylene composites. Polym Int 53:1624-1638. https://doi.org/10.1002/pi.1453

Keener TJ, Stuart RK, Brown TK (2004) Maleated coupling agents for natural fibre composites. Compos A Appl Sci Manuf 35:357-362 
La Mantia FP, Morreale M (2011) Green composites: a brief review. Compos Part A Appl Sci Manuf 42:579-588

Masek A, Zaborski M, Kosmalska A, Chrzescijanska E (2012) Eco-friendly elastomeric composites containing Sencha and Gun Powder green tea extracts. Comptes Rendus Chim 15:331-335. https://doi.org/10.1016/j.crci.2011.11.013

Masłowski M, Miedzianowska J, Strzelec K (2017) Natural rubber biocomposites containing corn, barley and wheat straw. Polym Test 63:84-91. https://doi.org/10.1016/j. polymertesting.2017.08.003

Masłowski M, Miedzianowska J, Strąkowska A et al (2018a) The use of rye, oat and triticale straw as fillers of natural rubber composites. Polym Bull 75:4607-4626. https://doi. org/10.1007/s00289-018-2289-y

Masłowski M, Miedzianowska J, Strzelec K (2018b) Influence of wheat, rye, and triticale straw on the properties of natural rubber composites. Adv Polym Technol. https://doi.org/10. 1002/adv.21958

Mohanty S, Verma SK, Nayak SK, Tripathy SS (2004) Influence of fiber treatment on the performance of sisal-polypropylene composites. J Appl Polym Sci 94:1336-1345. https:// doi.org/10.1002/app.21161

Murciano Martínez P, Bakker R, Harmsen P et al (2015) Importance of acid or alkali concentration on the removal of xylan and lignin for enzymatic cellulose hydrolysis. Ind Crops Prod 64:88-96. https://doi.org/10.1016/j.indcrop. 2014.10.031

Mwaikambo LY, Ansell MP (1999) The effect of chemical treatment on the properties of hemp, sisal, jute and kapok for composite reinforcement. Die Angew Makromol Chem 272:108-116. https://doi.org/10.1002/(SICI)15229505(19991201)272:1<108::AID-APMC108>3.0.CO;2-9

Payne AR (1965) Effect of dispersion on the dynamic properties of filler-loaded rubbers. J Appl Polym Sci 9:2273-2284. https://doi.org/10.1002/app.1965.070090619

Ramamoorthy SK, Skrifvars M, Rissanen M (2015) Effect of alkali and silane surface treatments on regenerated cellulose fibre type (Lyocell) intended for composites. Cellulose 22:637-654. https://doi.org/10.1007/s10570-014-0526-6
Ramli R, Yunus RM, Beg MDH (2011) Effects of fiber loading, fiber type, its mesh sizes, and coupling agent on the properties of oil palm biomass/polypropylene composites. J Compos Mater 45:2165-2171. https://doi.org/10.1177/ 0021998311401069

Sanjay M, Yogesha B (2017) Studies on natural/glass fiber reinforced polymer hybrid composites: an evolution. Mater Today Proc 4:2739-2747

Sathishkumar TP, Navaneethakrishnan P, Shankar S, Rajasekar R (2014) Mechanical properties and water absorption of short snake grass fiber reinforced isophthallic polyester composites. Fibers Polym 15:1927-1934. https://doi.org/ 10.1007/s12221-014-1927-8

Shah AUR, Prabhakar MN, Il Song J (2017) Current advances in the fire retardancy of natural fiber and bio-based composites-a review. Int J Precis Eng Manuf Green Technol 4:247-262. https://doi.org/10.1007/s40684-017-0030-1

Thakur MK, Gupta RK, Thakur VK (2014) Surface modification of cellulose using silane coupling agent. Carbohydr Polym 111:849-855. https://doi.org/10.1016/j.carbpol.2014.05. 041

Trigui A, Karkri M, Peña L et al (2013) Thermal and mechanical properties of maize fibres-high density polyethylene biocomposites. J Compos Mater 47:1387-1397. https://doi. org/10.1177/0021998312447648

Vijaya Ramnath B, Manickavasagam VM, Elanchezhian C et al (2014) Determination of mechanical properties of intralayer abaca-jute-glass fiber reinforced composite. Mater Des 60:643-652. https://doi.org/10.1016/j.matdes.2014. 03.061

Wang M-J (1998) Effect of polymer-filler and filler-filler interactions on dynamic properties of filled vulcanizates. Rubber Chem Technol 71:520-589. https://doi.org/10. 5254/1.3538492

Yusriah L, Sapuan SM, Zainudin ES, Mariatti M (2014) Characterization of physical, mechanical, thermal and morphological properties of agro-waste betel nut (Areca catechu) husk fibre. J Clean Prod 72:174-180. https://doi. org/10.1016/j.jclepro.2014.02.025 